California State University, Monterey Bay

Digital Commons@ @ CSUMB

Fall 2017

\title{
Physical Factors Influencing Phytoplankton Abundance in Southern Monterey Bay
}

C. Ryan Manzer

California State University, Monterey Bay

Follow this and additional works at: https://digitalcommons.csumb.edu/caps_thes_all

\section{Recommended Citation}

Manzer, C. Ryan, "Physical Factors Influencing Phytoplankton Abundance in Southern Monterey Bay" (2017). Capstone Projects and Master's Theses. 227.

https://digitalcommons.csumb.edu/caps_thes_all/227

This Master's Thesis (Open Access) is brought to you for free and open access by the Capstone Projects and Master's Theses at Digital Commons @ CSUMB. It has been accepted for inclusion in Capstone Projects and Master's Theses by an authorized administrator of Digital Commons @ CSUMB. For more information, please contact digitalcommons@csumb.edu. 


\title{
PHYSICAL FACTORS INFLUENCING PHYTOPLANKTON ABUNDANCE IN SOUTHERN MONTEREY BAY
}

\author{
A Thesis \\ Presented to the \\ Faculty of \\ Moss Landing Marine Laboratories \\ California State University Monterey Bay \\ In Partial Fulfillment \\ of the Requirements for the Degree \\ Master of Science \\ in \\ Marine Science \\ by \\ C. Ryan Manzer
}

Fall 2017 


\section{CALIFORNIA STATE UNIVERSITY MONTEREY BAY}

The Undersigned Faculty Committee Approves the

Thesis of C. Ryan Manzer:

\section{PHYSICAL FACTORS INFLUENCING PHYTOPLANKTON}

ABUNDANCE IN SOUTHERN MONTEREY BAY

Tom Connolly, Chair

Physical Oceanography

Kenneth H. Coale

Chemical Oceanography

Nicholas A. Welschmeyer

Biological Oceanography

\section{Digitally signed by Kris Roney}

Date: 2017.12.18 11:21:11 -08'00'

Kris Roney, Dean

Associate VP for Academic Programs and Dean of Undergraduate and Graduate Studies

Approval Date 
Copyright () 2017

by

C. Ryan Manzer

All Rights Reserved 


\author{
Abstract \\ Physical Factors Influencing Phytoplankton Abundance in Southern \\ Monterey Bay \\ by \\ C. Ryan Manzer \\ Master Degree in Marine Science \\ California State University Monterey Bay, 2017
}

As the base of almost all marine food webs, phytoplankton play a dominant role in determining the productivity of marine ecosystems. Recent studies have highlighted the dynamic variability of phytoplankton abundance in nearshore ecosystems over synoptic time scales. The inability of satellite ocean color monitoring to resolve chlorophyll values at a resolution less than $1 \mathrm{~km}$ and a reliable temporal resolution of $\sim 8$ days means this data cannot adequately capture the impact of nearshore dynamics on chlorophyll abundance and distribution. Therefore, a greater understanding of the physical mechanisms that contribute to this variability is required to assess impacts of current as well as future weather patterns on these ecosystems.

In this study, chlorophyll fluorescence data from a nearshore location in the south Monterey Bay was used to identify the timing and duration of increases in phytoplankton concentrations. Physical parameters, including wind stress and water temperature were analyzed to determine whether upwelling and/or upwelling relaxation events correlate with observed blooms. A significant negative correlation between water temperature and chlorophyll was found for the two summer seasons studied $(2012,2013)$ which suggess that increases in chlorophyll concentrations are more likely due to advection than biological reproduction. The results of this study suggest that phytoplankton are advected into the southern Monterey Bay during wind relaxation events of great enough magnitude to disrupt dominant circulation patterns. These impacts are site specific and demonstrate the degree to which the ecological subsidies can vary over small spatial ranges at synoptic scales. 


\section{TABLE OF CONTENTS}





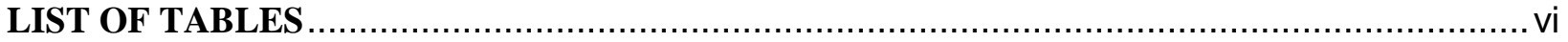



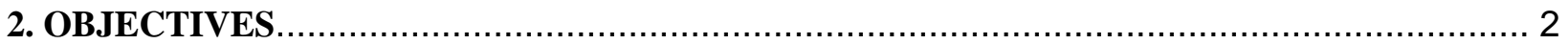

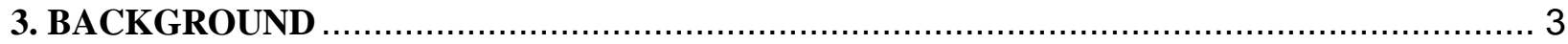

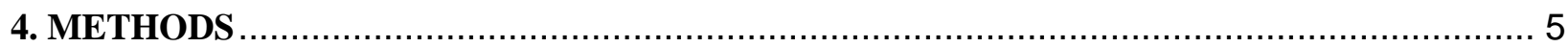

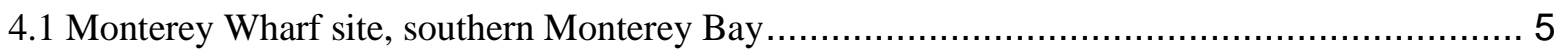

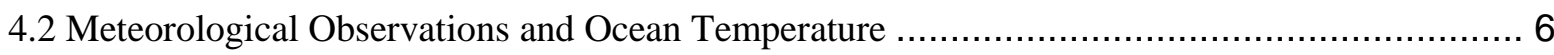

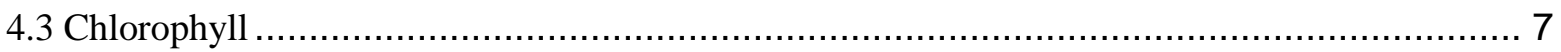

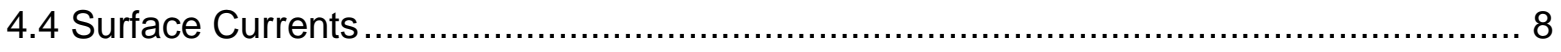

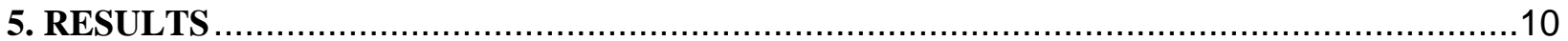

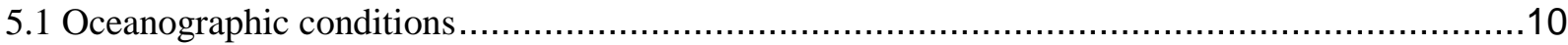

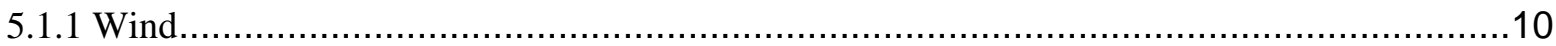

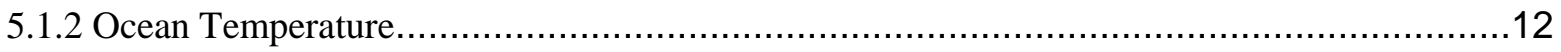

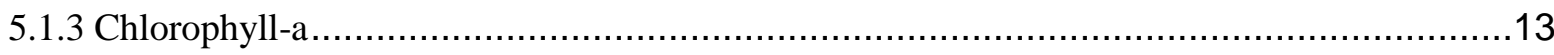

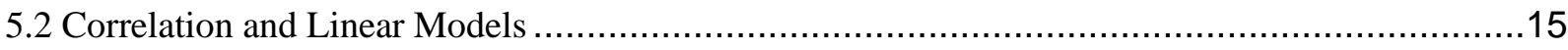

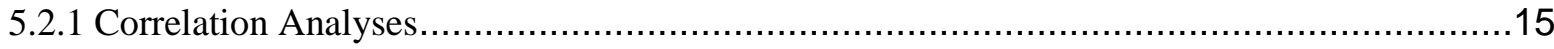

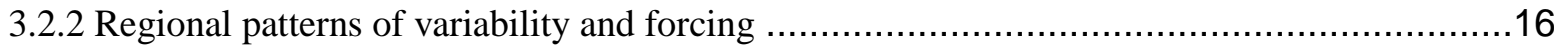

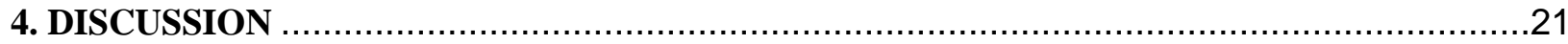

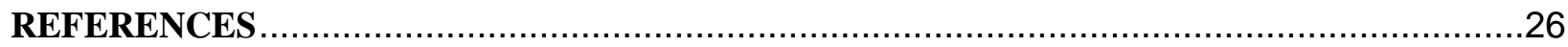

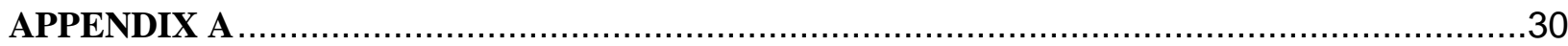

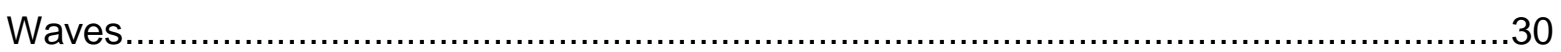




\section{LIST OF FIGURES}



2. HF Radar coverage, selected grid points................................

3. Low pass filtered regional wind stress.................................. 10

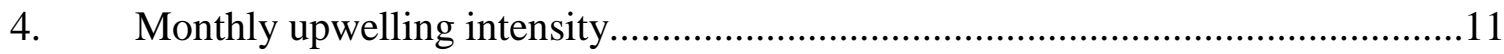

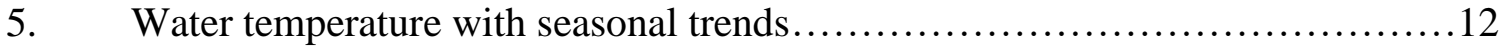

6. Chlorophyll concentration......................................... 13

7. Linear Regressions for Chlorophyll and Temperature...................... 16

8. 2012 Chlorophyll, Temperature, Wind Stress, Surface Currents.................17

9. $\quad 2013$ Chlorophyll, Temperature, Wind Stress, Surface Currents................18

10. Monterey Bay SST, Surface Currents with Time Series....................20

11. Upwelling circulation schematic....................................22



13. Polar histogram of wave direction..................................... 30

14. Hourly Significant Wave Height with 30 day average........................

15. Variance Conserving Power Spectral Density of Wave Height...................32 


\section{LIST OF TABLES}

1. Chlorophyll Cross Correlation Values ................................... 15 


\section{INTRODUCTION}

Coastal upwelling ecosystems represent the most biologically productive systems in the world's oceans. The high rates of primary productivity in these regions support rich coastal marine ecosystems and productive commercial fisheries (Pauly \& Christensen, 1995). Persistent equatorward winds drive the upwelling of nutrient rich water to the euphotic zone which supports high phytoplankton abundance. Variation in the strength of these physical processes has been shown to dramatically affect primary production rates, with cascading effects on higher trophic levels (Menge et al., 2009, Barth et al., 2007, Krenz et al., 2011). Characterizations of these upwelling systems are often made on large spatial/temporal scales and discussed in terms of seasonal/monthly averages (e.g. Thomas et al., 2001, Pennington \& Chavez, 2000).

Previous studies on upwelling and associated ecological responses in the Monterey Bay have shown the large-scale processes that occur over seasonal time scales can obscure finer-scale variability at synoptic time scales. Pennington \& Chavez (2000) constructed average year profiles of salinity, temperature, nitrate, and chlorophyll from a 7.5 year time series of measurements taken in the Monterey Bay. These average year profiles illustrated a pattern of upwelling and, after some time lag primary productivity. Beginning in February, this process reaches a maximum value in June and declines in the July-August period. However, when the individual years of this time series were analyzed they revealed that the gradual trends in the “average year" masked short term variation. Both upwelling and chlorophyll abundance showed strong episodic behavior on a time scales of weeks throughout the years examined (1989-1996). More recently, short episodic blooms of phytoplankton have been observed even during steady upwelling conditions along the exposed rocky coast of California (McPhee-Shaw et al., 2011). At three different sites along the coast of Chile, Wieters et al. (2003) found that the highest degree of variance in chlorophyll occurred on a synoptic time scales (1-10 days) with wide variation across relatively small spatial scales $(\leq 20 \mathrm{~km})$. These studies suggest that different processes drive the dynamics of nearshore and coastal phytoplankton concentrations at seasonal and synoptic time scales.

Two different advective mechanisms have previously been identified as potential drivers of episodic bloom events: wind relaxation and wave-driven transport. Wieters et al. (2003) found 
most of the observed blooms occurred during periods of wind reversals and consequent upwelling relaxation. Landward advection of water due to upwelling relaxation was proposed as the mechanism transporting offshore concentrations of phytoplankton to the nearshore. McPheeShaw et al. (2011) found that, during constant upwelling conditions along the rocky, exposed coast of central California, blooms predominantly occurred following periods of high wave energy and suggested wave driven mass transport as the mechanism causing the accumulation of buoyant phytoplankton in the nearshore waters. These two studies found specific periods during which the advective mechanisms described were significant determinants of phytoplankton blooms. Along the California coast, McPhee-Shaw et al. (2011) found the correlation between phytoplankton abundance and wave events to be particularly strong during the spring onset of the upwelling season. Wieters et al. (2003) found that upwelling relaxation correlated most strongly during the spring and summer periods. Additional work has shown that different advective mechanisms favor different taxonomic compositions of phytoplankton assemblages (Paquin, 2012). While both wave fields and pressure gradients driving wind patterns are regional in scale, the effects and biological response of nearshore ecosystems can be dominated by local conditions (Weiters et al. 2003, Narvaez et al. 2004).

\section{OBJECTIVES}

The objectives of this study are to determine the contributions of various physical factors to phytoplankton abundance in southern Monterey Bay. This study site was chosen due to the existing presence of an ongoing monitoring project conducted through the Central and Northern California Ocean Observing Network (CeNCOOS), the Moss Landing Marine Labs Environmental Biotechnology Lab (EBL), and the Monterey Abalone Company. Data from a suite of instruments deployed at the Monterey Wharf 2 were analyzed to identify specific chlorophyll increase events and characterize their magnitude and duration. The results of this study indicate the supply of phytoplankton to the nearshore environment in southern Monterey Bay is primarily episodic. During the summer months, when upwelling conditions were present, these episodic increases in phytoplankton were preceded by weakening or reversal of upwelling favorable winds as well as surface current circulation patterns associated with upwelling. This provides insight into both the mechanics governing phytoplankton delivery to the nearshore 
ecosystem currently as well as how changes in wind patterns and consequently circulation in the bay may affect the nearshore ecosystem. The specific questions addressed in this study are as follows:

1. Can phytoplankton bloom events in Southern Monterey Bay be attributed to upwelling relaxation and/or wave driven advection? If so, to what degree?

2. Is there seasonality to the correlation between specific advective mechanisms and phytoplankton abundance?

\section{BACKGROUND}

The general location of this study, Monterey Bay, is a large, open embayment located on the central California coast (Figure 1) and is characterized by persistent upwelling-favorable winds during the spring and summer. These winds cause upwelling along the exposed coastline and result in plumes of cold, nutrient-rich water coming to the surface to the north off Point Año Nuevo and to the south off Point Sur (Breaker \& Broenkow, 1994). Advection of water from Point Año Nuevo is the main source of upwelled surface water into the Monterey Bay (Rosenfeld et al., 1994). Historically, three oceanographic periods have been defined for the Monterey Bay. These are the spring-summer upwelling season, late summer-fall oceanic season, and winter Davidson current season (Skogsberg, 1936; Skogsberg and Phelps, 1946; Pennington \& Chavez, 2000). 


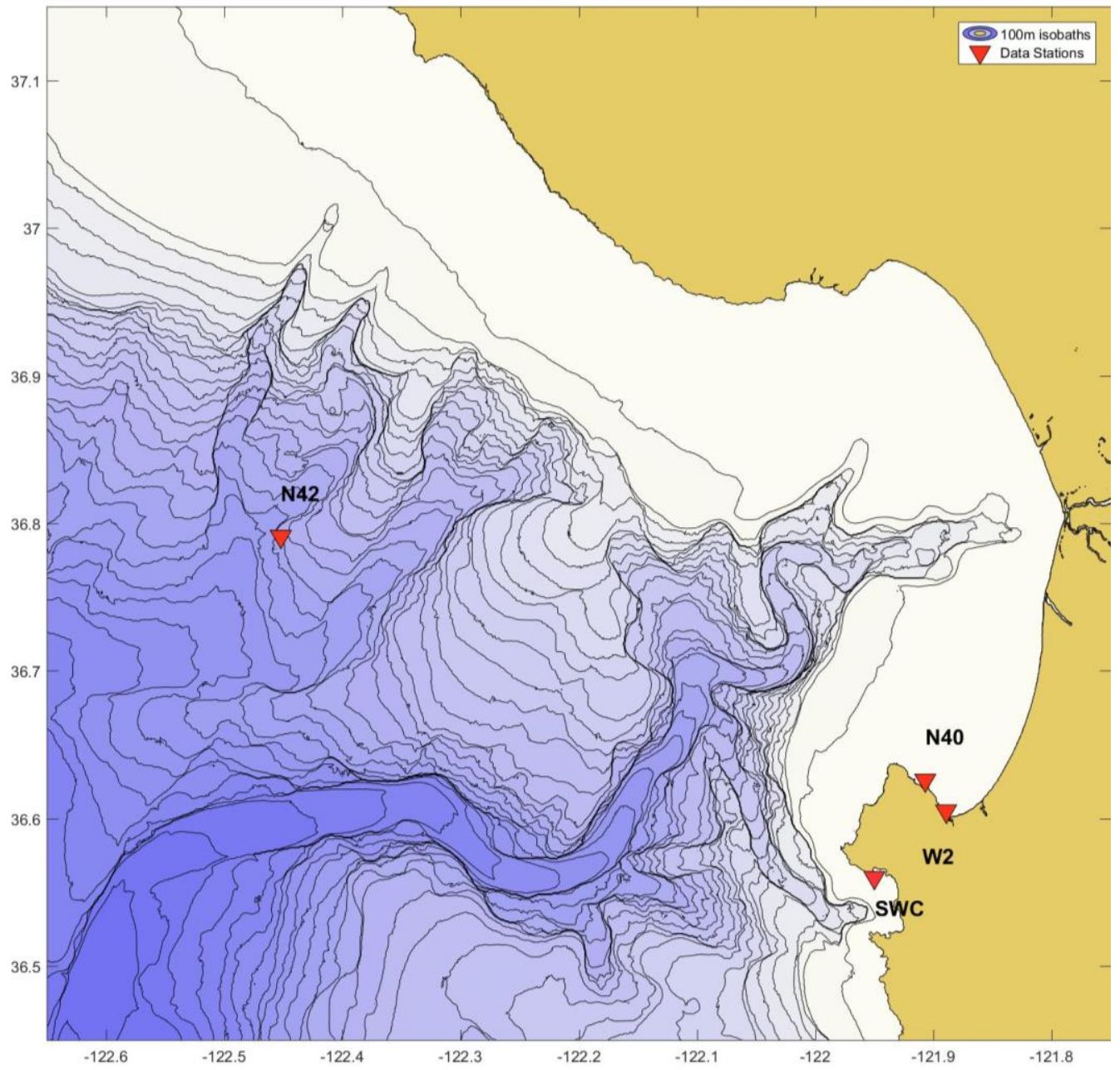

Figure 1. Study site, Monterey Bay with bathymetry. Data stations include NDBC buoys 46042 (N42), 46240 (N40), Stillwater Cove (SWC), and Municipal Wharf 2 (W2).

On synoptic scales, it has been hypothesized that upwelled surface water entering Monterey Bay typically advects toward the southeast from northwest of Santa Cruz toward the middle of the bay with the main water mass flowing southward and exiting the bay past the outer coast of the Monterey peninsula (Figure 11. Graham \& Largier, 1997). Graham and Largier (1997) also indicate that slower ancillary flows occur closer to shore, which proceed southward from Moss Landing along the coast. This reduced flow closer to shore is thought to increase the residence time of water in the southeastern portion of the bay and helps account for increased surface temperatures regularly observed there (Graham \& Largier, 1997). This mechanism is 
fundamentally different from the buoyant surface plume in the north of the bay, to which the upwelling shadow is attributed.

A recent study by Paduan et al. (2016) utilizing a conditional averaging approach to analyze surface currents using specific wind parameters to select periods of interest has suggested that, contrary to earlier studies, upwelled water typically flows across the mouth of the bay without entering the bay. This is a result of previously documented anticyclonic flow outside the Monterey Bay and cyclonic flow inside the bay (Paduan \& Rosenfeld 1997, Paduan \& Cook 1997). The two contrasting current systems set up a transport barrier across the mouth of the bay and reduce exchange between the open ocean and inner bay waters. While the regional and local flows had been previously described, the change in current velocities due to the conditional averaging approach rather than a seasonal averaging resulted in this novel description of upwelling circulation. Woodson et al. (2009) demonstrated how local forcing mechanisms can interact with regional oceanographic conditions to produce drastic differences in water characteristics on small spatial scales. While more work has been done focusing on the northern region of Monetery Bay (Woodson et al. 2009, Ryan et al. 2009, Graham \& Largier 1997), similar discrepancies between regional and local conditions have been observed for the south Monterey Bay (Breaker \& Broenkow, 1994, Drake et al. 2005).

The majority of studies examining the synoptic scale variation of phytoplankton abundance and any potential relationships to physical advective mechanisms have focused on locations offshore of the cyclonic flow within the Monterey Bay (Pitskalin et al. 1996, Service et al. 1998, Olivieri \& Chavez 2000, Pennington \& Chavez 2000, Urmy \& Horne 2016) or the northeastern section of the Monterey Bay (Ryan et al. 2010, Sevadjin et al. 2014).

\section{METHODS}

\subsection{Monterey Wharf site, southern Monterey Bay}

Monitoring of oceanographic conditions at the Monterey Wharf II in southern Monetery Bay is conducted through the Central and Northern California Ocean Observing System (CeNCOOS). Instruments are maintained by Moss Landing Marine Laboratories Environmental Biotechnology Lab (Jason Smith, Principal Investigator). Chlorophyll fluorescence, salinity, turbidity, temperature, $\mathrm{pH}$, and dissolved oxygen were measured every 5 minutes at the 
Monterey Municipal Wharf 2 (W2, Figure 1) from June 25, 2012 through October 11, 2013 by a YSI 6600 V2-4 Sonde with a chlorophyll fluorometer, phycoerithrin fluorometer, turbidity sensor, fast response $\mathrm{pH}$ electrode (glass bulb), conductivity-temperature sensor and an optical dissolved oxygen sensor. All optical sensors were equipped with mechanical wipers and cleaned every 15 minutes. All sensors were wrapped in copper tape to minimize fouling and the sensor head was encased in a brass/copper guard as additional fouling protection. The device was physically inspected on a monthly basis. Calibrations to establish zero points for chlorophyll, turbidity, and phycoerithrin were performed using filtered seawater on quarterly basis during equipment servicing. The site where this device is located is a partially sheltered location on the coast of the Monterey peninsula in the southern Monterey Bay at the Monterey Abalone Company site (W2, Figure 1). The servicing schedule for this station resulted in fragmented data. Only temperature could successfully be reconstructed into contiguous time series. Chlorophyll, the metric of prime focus, was confined to data fragments, none of which extended beyond 4 months in length.

\subsection{Meteorological Observations and Ocean Temperature}

Hourly averages of the standard meteorological data were obtained from National Data Buoy Center (NDBC) buoy 46042 (N42, Figure 1). Wind stress was derived from hourly averaged wind speed measurements using the formulation of Large \& Pond (1981). The vectors are decomposed into northward, eastward, alongshore, and cross-shore components using principal axis analysis (Emery and Thomson, 2001). As negative along-shore wind stress is upwelling favorable for this region, it was used as a proxy for upwelling.

Additional data on sea surface temperature was collected from the NDBC buoy 46240 (N40 Figure1), commonly referred to as the Cabrillo Point buoy. In order to construct a longer time series of water temperature at Wharf 2 , a linear regression $\left(R^{2}=0.937\right)$ between the temperature measured at Cabrillo Point and Wharf 2 was derived to generate a more complete time series. In order to further analyze the movement of water masses around the Monterey Peninsula, temperature records were collected from long term thermistor deployments in Stillwater Cove at depths of 0, 5, 10, and 15 meters that are maintained by the Moss Landing Marine Labs Ichthyology Lab (Scott Hamilton, Principal Investigator). This location, while still relatively sheltered, gives an indication of changes in water temperature in the nearshore 
environment of the exposed outer coast, providing a contrast to the Monterey Wharf site within Monterey Bay.

As this study focuses on synoptic scale events, where applicable time series data was low pass filtered using the PL64 filter (Rosenfeld, 1983) with a 33 hour half amplitude period to remove frequencies that occurred within a 24 hour time period. Where time series lengths were 3 months or greater, additional harmonic analyses were performed to remove seasonal trends by fitting the data with annual and semiannual tidal constituents. Where the PL64 filter was not well suited for the data available, due to small gaps that were nonetheless too large to interpolate over, additional harmonic analyses were performed to extract variance associated with the diurnal tidal constituents responsible for the greatest variance (M2, K1, S1) following Woodson et al. (2009).

Due to the high degree of autocorrelation in oceanographic time series data, when performing any statistical tests an effective degrees of freedom calculation was performed. Decorrelation times were calculated by taking the first zero crossing in the autocorrelation spectrum of each variable. Effective degrees of freedom were calculated dividing the length of the time series by the decorrelation time and subtracting the appropriate value (e.g. N-1). Where cross correlations were performed, the longer of the two decorrelation times were used to generate the most conservative estimate of effective degrees of freedom, following Drake et al. (2005). These effective degrees of freedom were used whenever assessing the significance of correlation coefficients.

Satellite measurements of sea surface temperature (SST) were obatined from the NASA Group for High Resolution Sea Surface Temperature (GHRSST) project using a Level 4 processed AVHRR and AMSR-E microwave data product with a longitude/latitude resolution of $1 \mathrm{~km}$. This data is used to assess whether frontal patterns similar to those found in Woodson et al. (2009) were apparent along the inner coast of the Monterey Peninsula.

\subsection{Chlorophyll}

Because no segments of chlorophyll data are greater than 4 months in duration, seasonal variation in chlorophyll was accounted for by removing linear trends from the data set. All observations were low pass filtered using the PL64 filter to remove high frequency variability. 
The non-normal distribution of chlorophyll data was accounted for in correlation analyses by taking the natural log of the detrended fluorescence measurements.

\subsection{Surface Currents}

High frequency (HF) radar derived surface current data was obtained from the Scripps Institute of Oceanography using latitude boundaries of approximately 35 to 37 degrees north, longitude boundaries of -120 to -122.4 degrees, and $2 \mathrm{~km}$ resolution. While HF radar coverage was inconsistent during the months of this study (June 2012 to October 2013), the data available was useful in determining general trends and large scale patterns in surface current circulation in the Monterey Bay. Surface currents were examined in combination with temperature time series to determine the advective effects of surface currents on distinct water masses. The time series of surface current data was analyzed to determine those grid components with greatest coverage, as determined by the number of valid measurements, during the two summer periods of greatest interest. Tidal velocities were filtered out from surface current data using the t_tide MATLAB function for those previously listed tidal constituents. (Pawlowicz et al 2002).

After being identified, those grid points with the greatest data coverage were averaged to further provide a general understanding of surface current patterns experienced in the Monterey Bay. Five grid points in central Monterey Bay had the lowest number of missing values (Figure 2). These points were averaged between respective locations to provide a mean vector of surface current flow for Monterey Bay. Time series of alongshore and cross-shore components of surface currents were compared with water temperature measured at Wharf 2 and Stillwater Cove to examine any relationship between large scale circulation patterns and synoptic scale changes in the nearshore environment. 


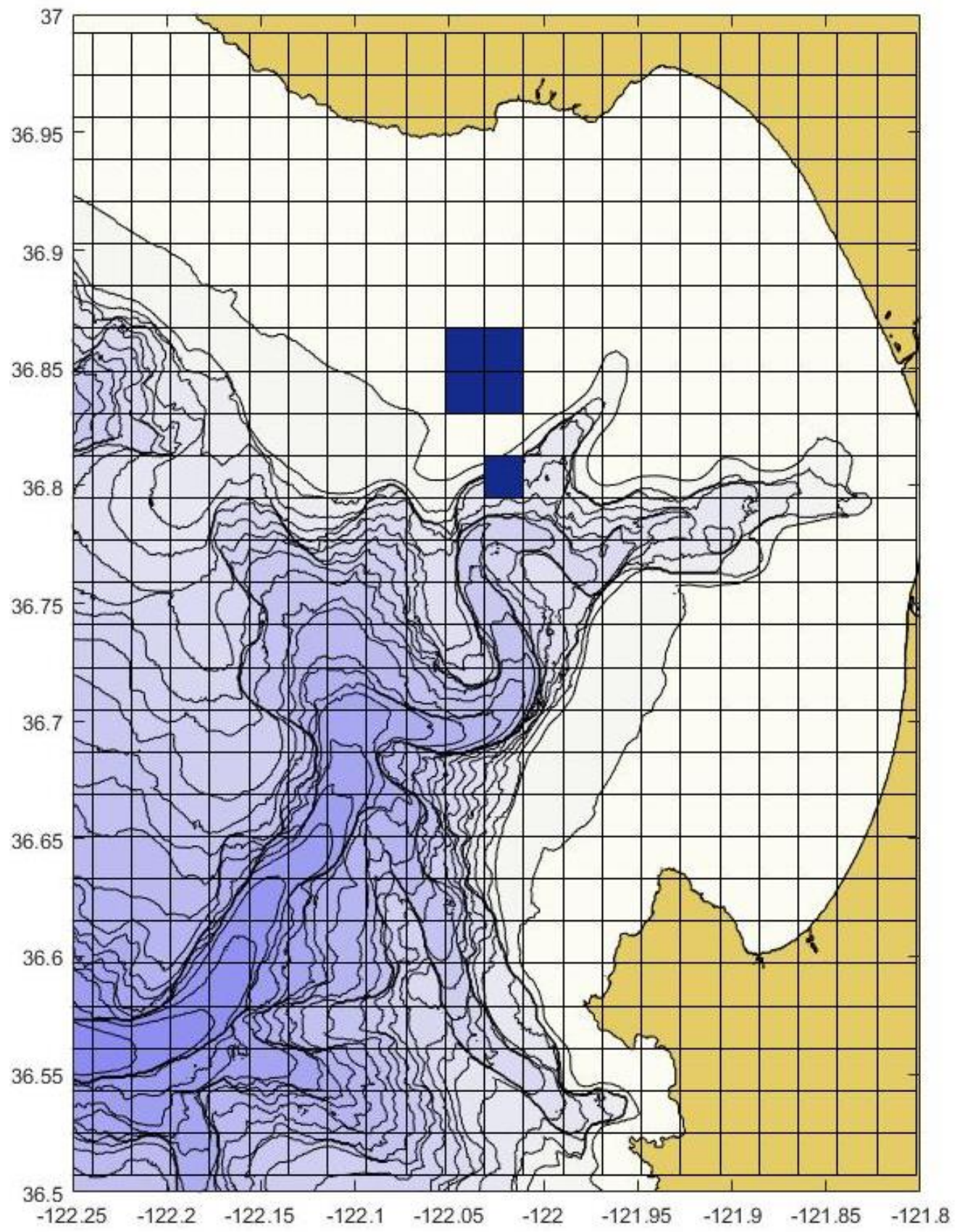

Figure 2: HF Radar grid for Monterey Bay. The solid grid squares represent the points used to summarize general flow in Monterey Bay.

Cross correlation analyses were performed between filtered log chlorophyll values and all physical parameters collected. Correlations were calculated using a maximum lag of 7 days and significance was determined using effective degrees of freedom. 


\section{RESULTS}

\subsection{Oceanographic conditions}

\subsubsection{Wind}

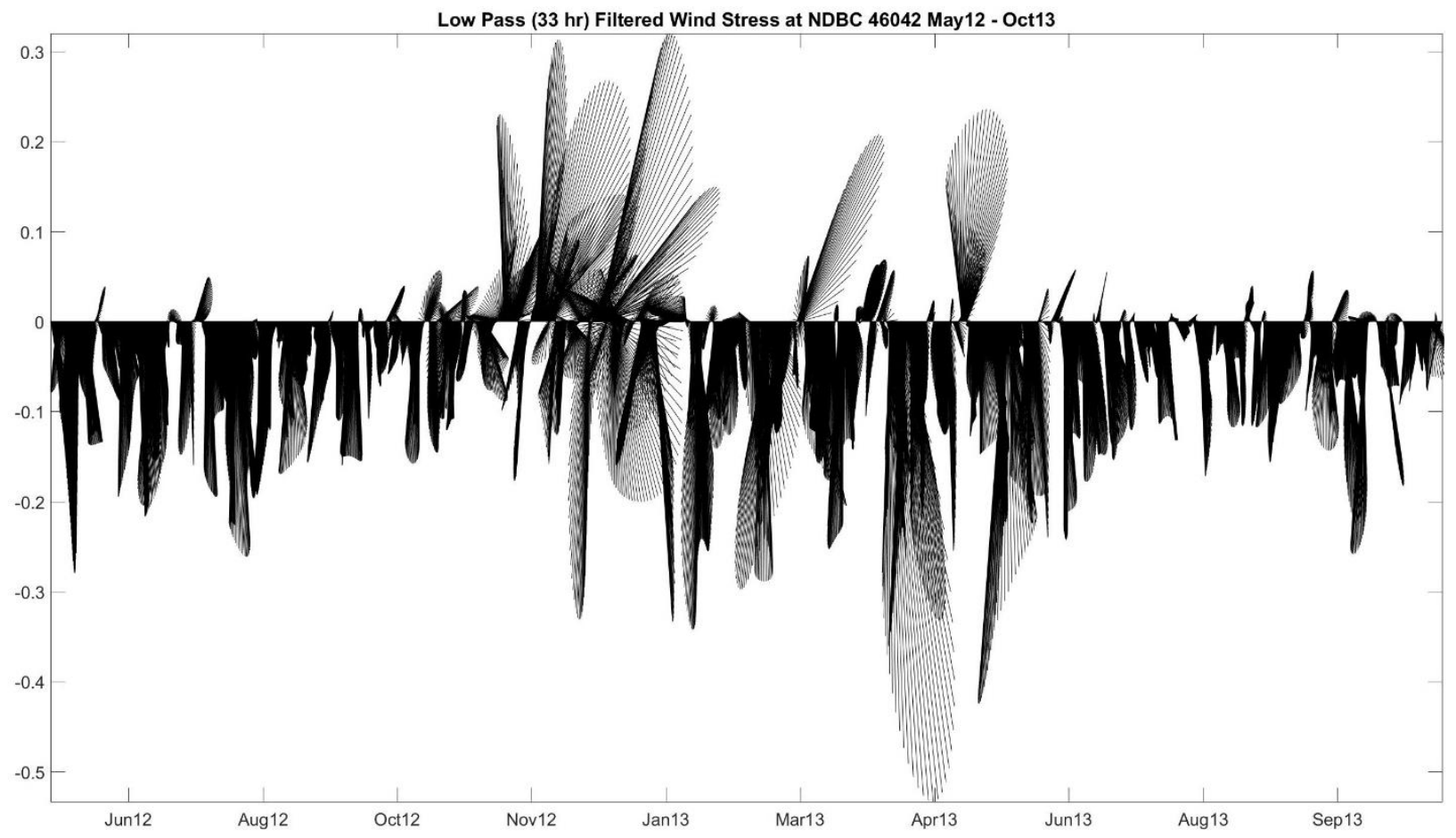

Figure 3. Low pass filtered wind stress measured at NDBC 46042 from May 2012 to October 2013

Wind stress was primarily upwelling favorable with primarily southeasterly winds occurring in the summer periods of each year studied (Figure 3). Upwelling favorable winds $\left(300^{\circ}\right.$ to $\left.350^{\circ}\right)$ occurred, with some reversals, throughout most of the study period. This aligns closely with the angle of the coastline. Both summers studied experienced upwelling reversals. The intermittency of wind stress can be quantified using the ratio of the inverse mean value (positive indicating upwelling favorable conditions) to the standard deviation $\left(\mu \tau_{\mathrm{y}} / \sigma \tau_{\mathrm{y})}\right.$ for each month, following Huyer (1983). 


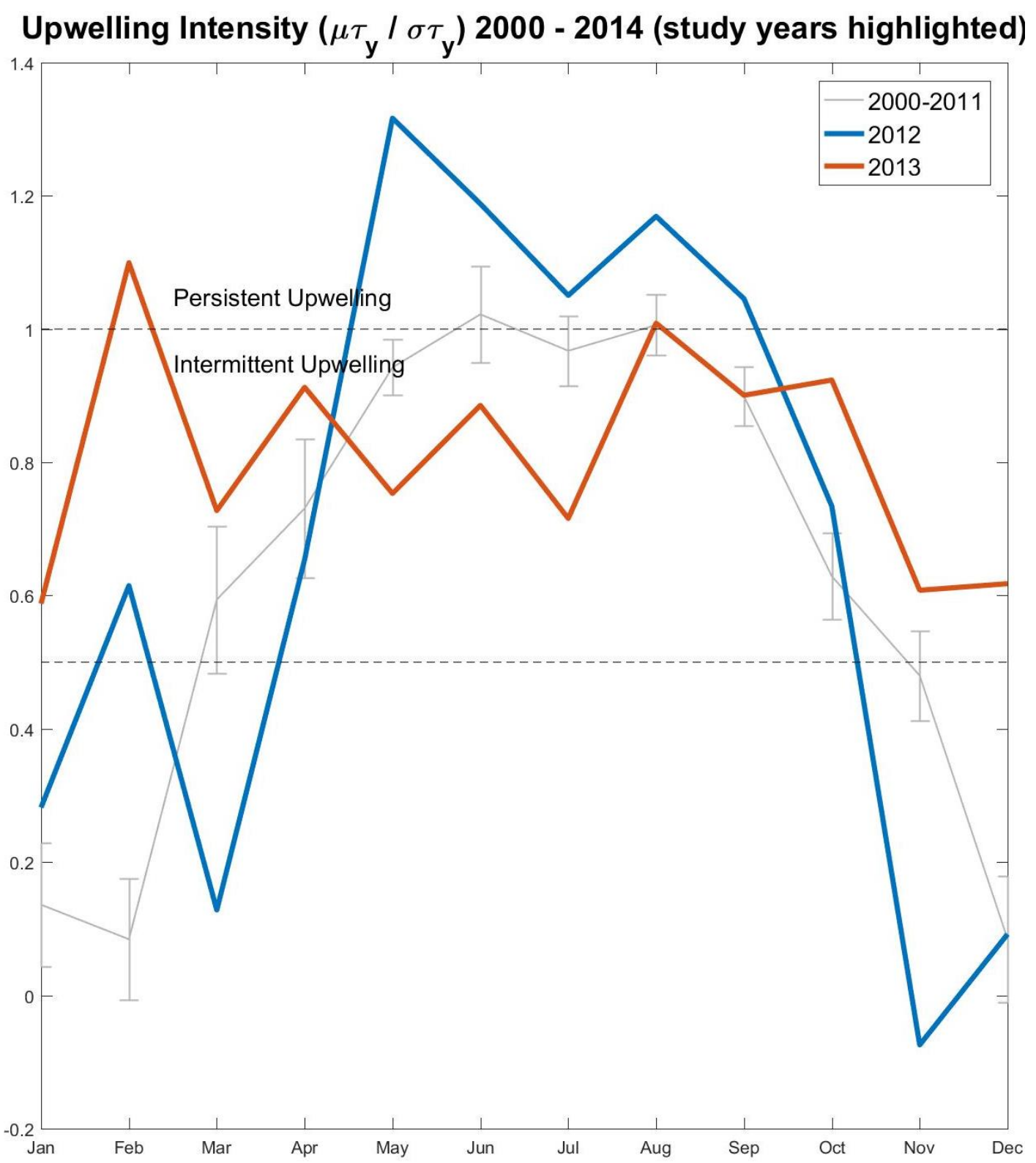

Figure 4. Monthly calculations of upwelling intensity index $\left(\mu \tau_{\mathrm{y}} / \sigma_{\mathrm{y}}\right)$. Dashed lines at 0.5 and 1.0 indicate thresholds for intermittent and persistent upwelling respectively. Error bars represent the standard error of average upwelling intensity for $2000-2011$.

Values greater than 1 indicate persistent upwelling. Values between 1 and 0.5 indicate the presence of intermittent upwelling. Values below 0.5 indicate the scale of variability relative to mean wind stress was such that an upwelling condition did not likely have a chance to set up. Comparisons were made between 2012 and 2013 to examine how consistent the upwelling 
conditions experienced by the Monterey Bay were during the course of this study (Figure 4). The mean values for 2000 through 2011 were computed, along with standard error, to demonstrate how each year compared against long term averages.

2012 was characterized by little to no upwelling conditions in early spring and then a rapid increase to persistent upwelling by May. This persistent upwelling condition was maintained through September, after which conditions rapidly returned to a state of nonupwelling. In contrast, 2013 was characterized almost entirely by an intermittent upwelling condition. Ratio values only exceeded 1 for two non-consecutive months and never fell below 0.5. These results, when compared to the long term average, show that neither year was exactly typical, although the pattern exhibited in 2012 was more consistent with the historical average.

\subsubsection{Ocean Temperature}

Water temperature as measured at Wharf 2 showed high frequency variation as well as seasonal trends. Comparisons were made between regional oceanic conditions as measured at N42, exposed coastal conditions as measured at Stillwater Cove, and the protected coastal conditions found at Wharf 2 (Figure 5).
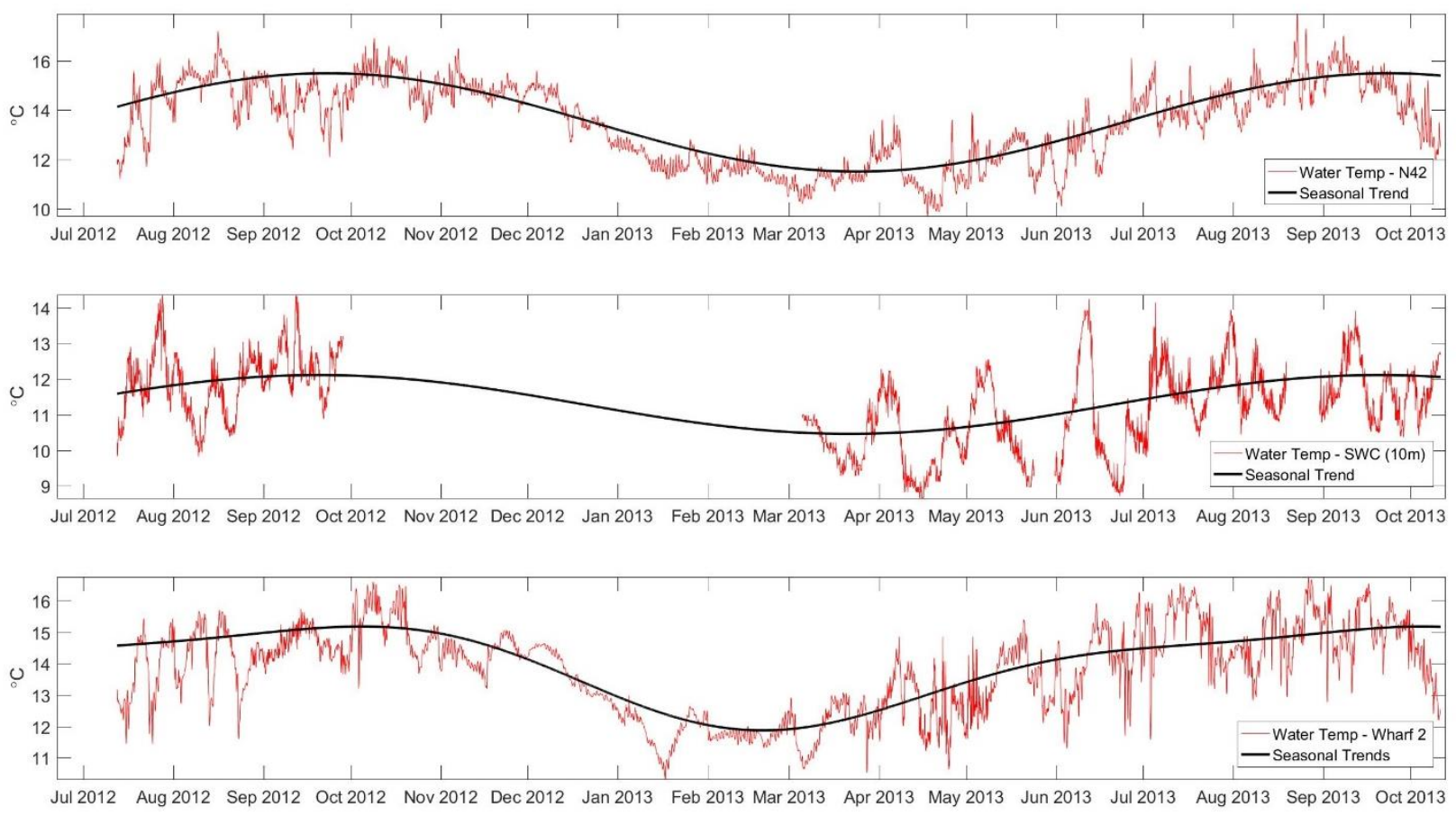

Figure 5. Water temperature at 3 stations with seasonal trends. 
The large amount of missing data for Stillwater Cove contributed to the depressed seasonal trends extrapolated using harmonic analysis. However, the overall seasonal trend exhibited across all stations is consistent. As will be seen later when we examine the two summers of our study period, despite relative proximity, the water temperature at Stillwater Cove and Wharf 2 exhibit very little correlation at the synoptic scale. While this is not necessarily unexpected given the difference in exposure between the two sites, it does illustrate how local site orientation and exposure can alter responses to regional forcing mechanisms.

\subsubsection{Chlorophyll-a}

Chlorophyll concentrations were highly variable between June 2012 and October 2013 (Figure 6). The one prolonged period of low fluorescence, from November 2012 to mid-February 2013, was punctuated with short term increases in chlorophyll concentrations.

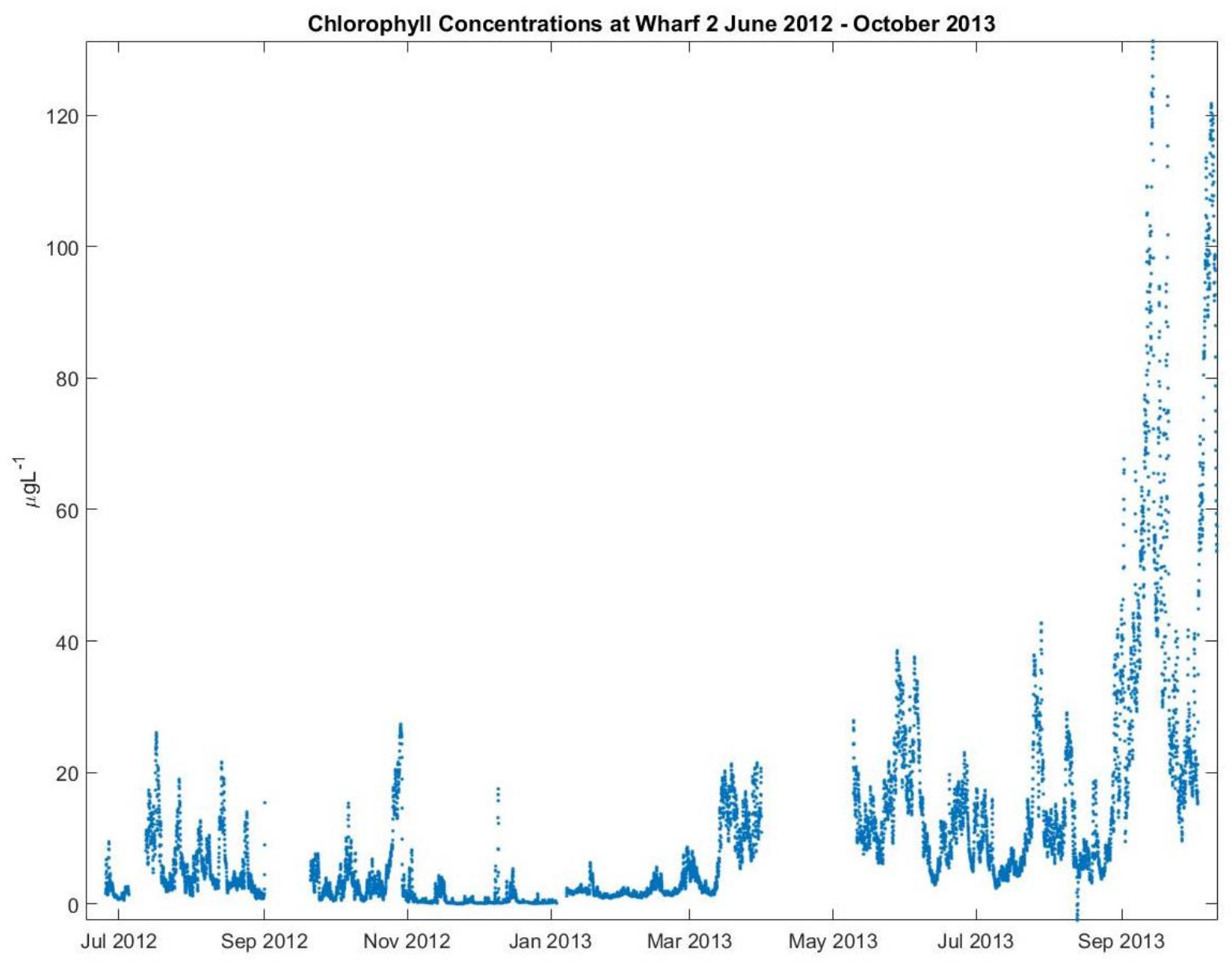


Figure 6. Chlorophyll values for June 2012 through October 2013 at Monterey Municipal Wharf 2.

The high chlorophyll concentrations that occurred in the fall of 2013 is considered atypical for the region. It did correlate with higher abundances of planktivorous fish species, sea lions, sea birds, and humpback whales which were observed in Monterey Bay later in the year than is common (Palacios et al., 2016). Despite the gap in data from 04-Sep-2012 to 20-Sep2012, it is unlikely that phytoplankton blooms of similar amplitude and duration occurred in the fall of 2012. A t-test using effective degrees of freedom determined 2013 was a significantly more biologically active year than 2012. During all seasons captured in the time series, short term variation (1-6 days) was evident in the chlorophyll values. 


\subsection{Correlation and Linear Models}

\subsubsection{Correlation Analyses}

Correlation analyses revealed that, of the various physical parameters measured, water temperature as measured at Wharf 2 was most consistently correlated with log chlorophyll concentrations (Table 1) which was the sole response variable.

\begin{tabular}{|c|c|c|c|c|c|}
\hline Predictor & Time Period & $\mathbf{R}$ & Lag (hrs) & Effective DF & $\mathbf{P}$ \\
\hline W2 Temp & Jul $12-$ Sep 12 & -0.656 & -13 & 26 & $1.5 \mathrm{e}^{-4}$ \\
\hline W2 Temp & Sep $12-$ Jan 13 & -0.239 & 163 & 23 & 0.25 \\
\hline W2 Temp & Jan 13 - Mar 13 & 0.545 & -46 & 21 & $7.2 \mathrm{e}^{-3}$ \\
\hline W2 Temp & May 13 - Aug 13 & -0.699 & 3 & 18 & $6.1 \mathrm{e}^{-4}$ \\
\hline W2 Temp & Aug 13 - Oct 13 & 0.333 & 136 & 14 & 0.21 \\
\hline N42 Temp & Jul $12-$ Sep 12 & 0.448 & 19 & 21 & 0.03 \\
\hline N42 Temp & Sep $12-$ Jan 13 & -0.135 & 157 & 24 & 0.51 \\
\hline N42 Temp & Jan $13-$ Mar 13 & 0.474 & -102 & 24 & 0.14 \\
\hline N42 Temp & May 13 - Aug 13 & -0.366 & -124 & 27 & 0.05 \\
\hline N42 Temp & Aug 13 - Oct 13 & 0.448 & 130 & 14 & 0.08 \\
\hline Alongshore Wind Stress & Jul $12-$ Sep 12 & -0.475 & -131 & 24 & 0.01 \\
\hline Alongshore Wind Stress & Sep 12 - Jan 13 & -0.146 & -26 & 45 & 0.40 \\
\hline Alongshore Wind Stress & Jan $13-$ Mar 13 & -0.333 & -93 & 26 & 0.08 \\
\hline Alongshore Wind Stress & May 13 - Aug 13 & -0.411 & -147 & 27 & 0.03 \\
\hline Alongshore Wind Stress & Aug 13 - Oct 13 & 0.415 & 17 & 14 & 0.11 \\
\hline Cross shore Wind Stress & Jul $12-$ Sep 12 & 0.360 & -69 & 26 & 0.06 \\
\hline Cross shore Wind Stress & Sep $12-$ Jan 13 & 0.123 & -165 & 45 & 0.41 \\
\hline Cross shore Wind Stress & Jan $13-$ Mar 13 & -0.431 & -90 & 26 & 0.02 \\
\hline Cross shore Wind Stress & May 13 - Aug 13 & 0.147 & 95 & 27 & 0.45 \\
\hline Cross shore Wind Stress & Aug 13 - Oct 13 & -0.308 & -18 & 14 & 0.25 \\
\hline Alongshore Surf Current & Jul $12-$ Sep 12 & 0.310 & -129 & 26 & 0.10 \\
\hline Alongshore Surf Current & Sep $12-$ Jan 13 & -0.171 & -149 & 45 & 0.25 \\
\hline Alongshore Surf Current & $\operatorname{Jan} 13-$ Mar 13 & --- & --- & --- & --- \\
\hline Alongshore Surf Current & May 13 - Aug 13 & -0.265 & -168 & 27 & 0.16 \\
\hline Alongshore Surf Current & Aug 13 - Oct 13 & 0.250 & 95 & 14 & 0.07 \\
\hline Cross shore Surf Currents & Jul $12-$ Sep 12 & -0.379 & -69 & 13 & 0.06 \\
\hline Cross shore Surf Currents & Sep $12-$ Jan 13 & -0.243 & -165 & 43 & 0.11 \\
\hline Cross shore Surf Currents & $\operatorname{Jan} 13-$ Mar 13 & --- & --- & --- & --- \\
\hline Cross shore Surf Currents & May 13 - Aug 13 & -0.454 & 95 & 27 & 0.01 \\
\hline Cross shore Surf Currents & Aug 13 - Oct 13 & 0.462 & -18 & 14 & 0.07 \\
\hline
\end{tabular}

Table 1. Correlation analyses using Wharf 2 Chlorophyll concentration as the dependent, or response, variable. Shaded rows indicate where correlations were significant. 
After correlation analyses revealed the closest correlation to exist between nearshore temperature and chlorophyll, linear regressions were calculated where the correlation was significant (Figure 7). These results demonstrate that, during the two summers studied, high chlorophyll was correlated with colder water temperature. This relationship is reversed during the one winter time segment observed during this study.

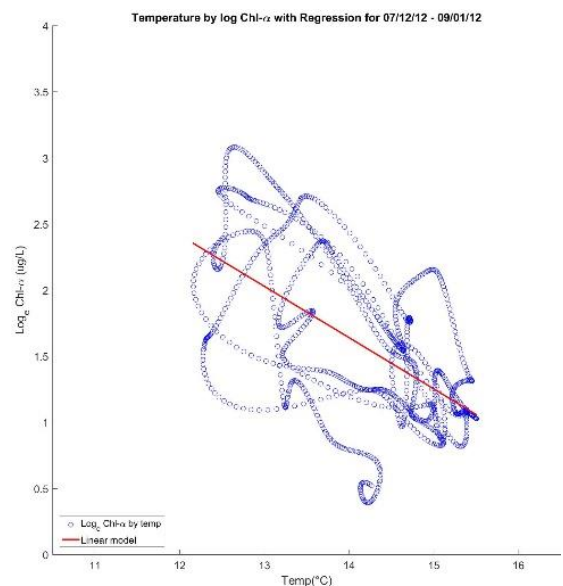

a.



b.



c.

Figure 7. Scatter plots of temperature and log chlorophyll at Wharf 2 with linear regression for Summer 2012 (a), Winter-Spring 2013 (b) and Summer 2013 (c).

\subsubsection{Regional patterns of variability and forcing}

In order to better understand the advective mechanisms that might be impacting water temperature at Wharf 2 time series of surface currents and wind stress were examined along with the temperature and chlorophyll time series. To contrast an exposed coastal environment with the semi-protected Wharf 2 study site, water temperature from Stillwater Cove was included as well (Figure 8,9). The inverse correlation between chlorophyll and temperature is apparent during both summer periods examined. 


\section{Chlorophll Concentration at Wharf 2 - 2012}



Water Temperature at Wharf 2 - 2012

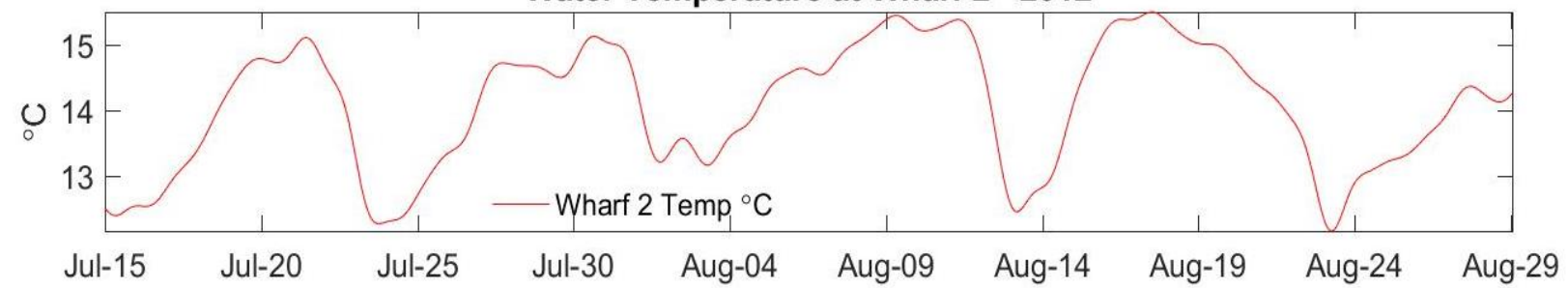

Average Surface Currents in Monterey Bay - 2012

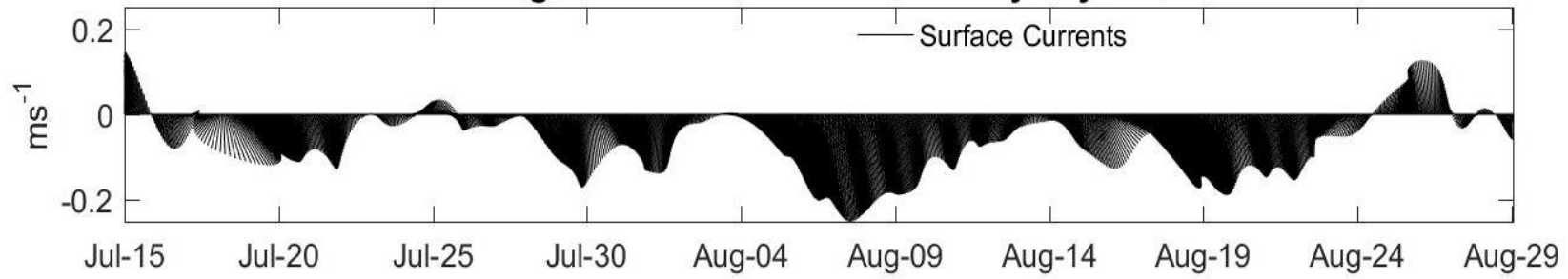

Water Temperature at Stillwater Cove $\mathbf{- 2 0 1 2}$



Low Pass Wind Stress at NDBC 46042 - 2012

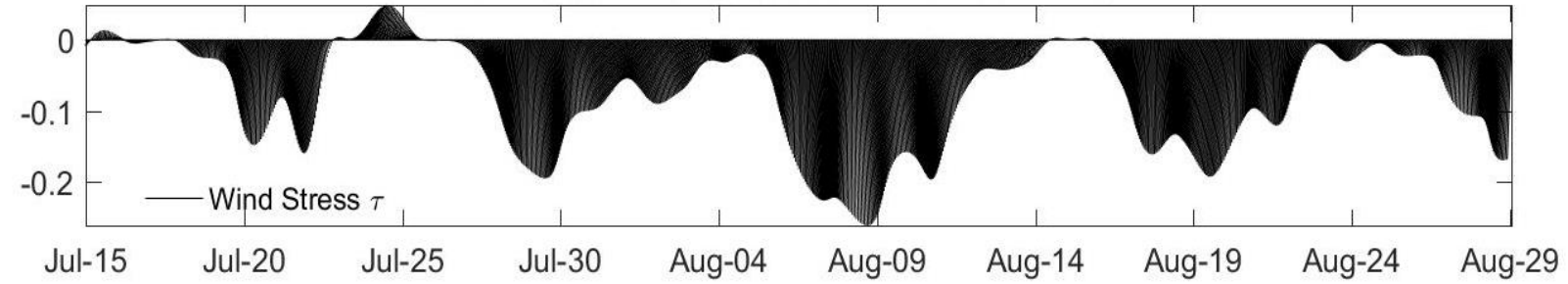

Figure 8. Chlorophyll and associated physical parameters for the summer of 2012. 
Chlorophll Concentration at Wharf 2 - 2013

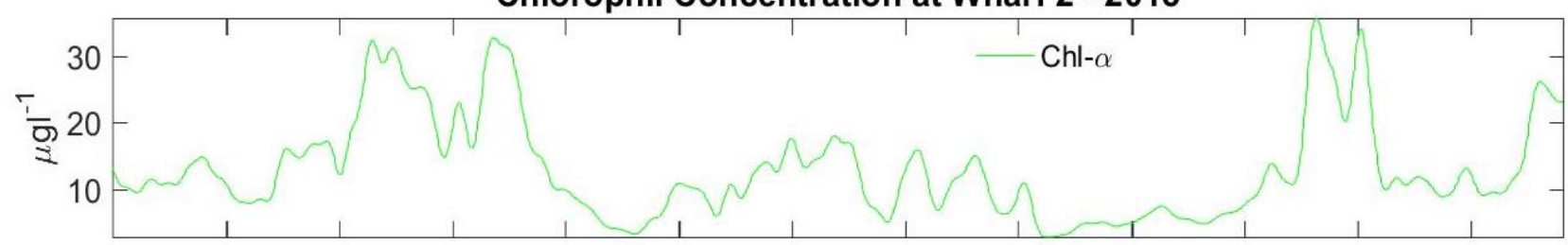

May-12 May-17 May-22 May-27 Jun-01 Jun-06 Jun-11 Jun-16 Jun-21 Jun-26 Jul-01 Jul-06 Jul-11

Water Temperature at Wharf 2 - 2013

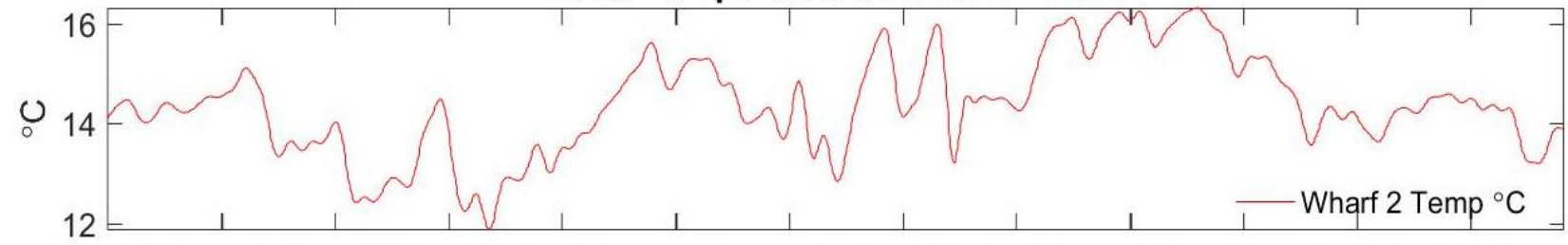

May-12 May-17 May-22 May-27 Jun-01 Jun-06 Jun-11 Jun-16 Jun-21 Jun-26 Jul-01 Jul-06 Jul-11

Average Surface Currents in Monterey Bay - 2013

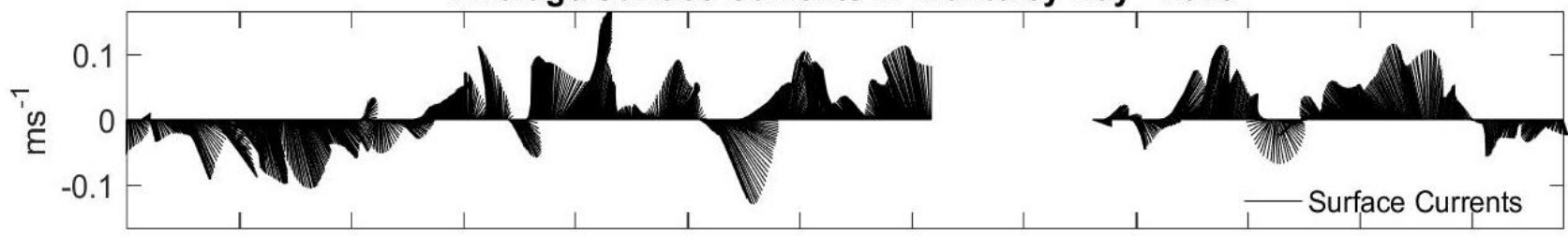

May-12 May-17 May-22 May-27 Jun-01 Jun-06 Jun-11 Jun-16 Jun-21 Jun-26 Jul-01 Jul-06 Jul-11

Water Temperature at Stillwater Cove $\mathbf{- 2 0 1 3}$

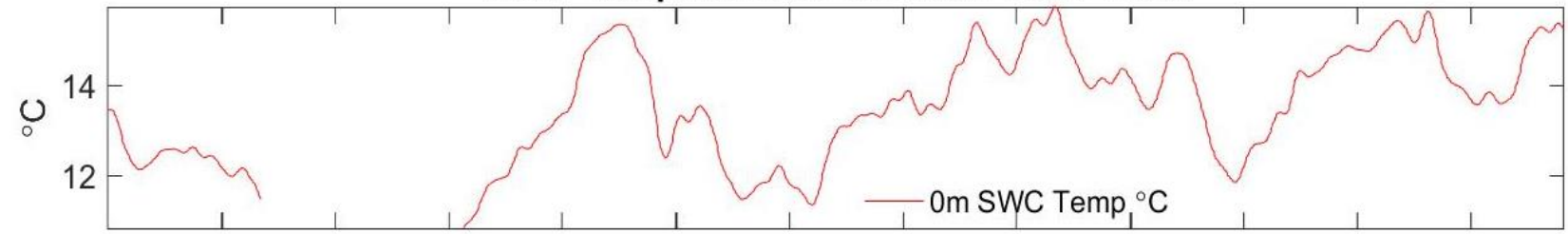

May-12 May-17 May-22 May-27 Jun-01 Jun-06 Jun-11 Jun-16 Jun-21 Jun-26 Jul-01 Jul-06 Jul-11

Low Pass Wind Stress at NDBC 46042 - 2013

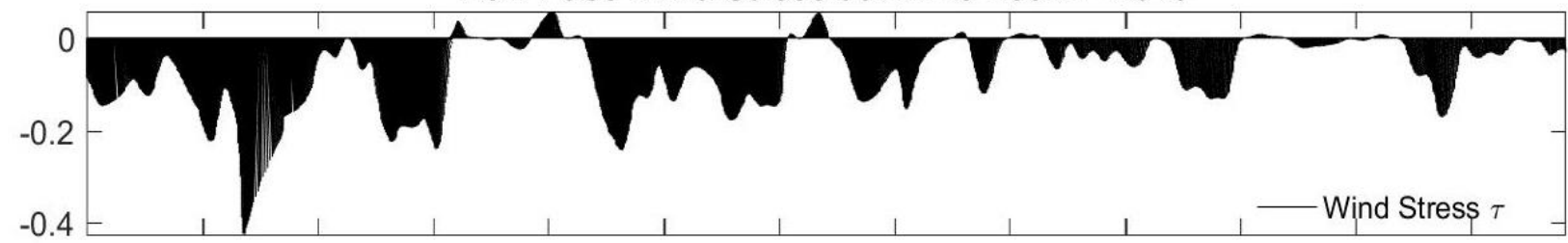

May-12 May-17 May-22 May-27 Jun-01 Jun-06 Jun-11 Jun-16 Jun-21 Jun-26 Jul-01 Jul-06 Jul-11

Figure 9. Chlorophyll and associated physical parameters for the summer of 2013. Y axes scales vary between years to display maximum variance for each parameter. $X$ axes scales vary based on length of available data. 
Average regional surface currents show less correlation with regional wind stress in 2013 than in 2012. This may be due to the differences in persistence of upwelling favorable winds (Figure 3). 2013 was characterized as having intermittent upwelling conditions throughout the entire year while 2012 had persistent upwelling during the late spring through early fall (May Oct) and rapid transitions to periods of no upwelling. Such conditions would result in less consistent wind patterns for surface currents to respond to. 


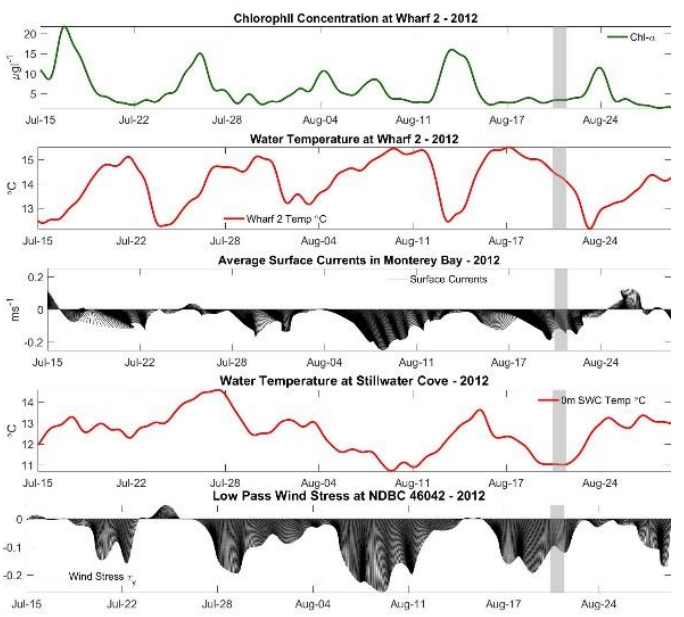

a.





b.

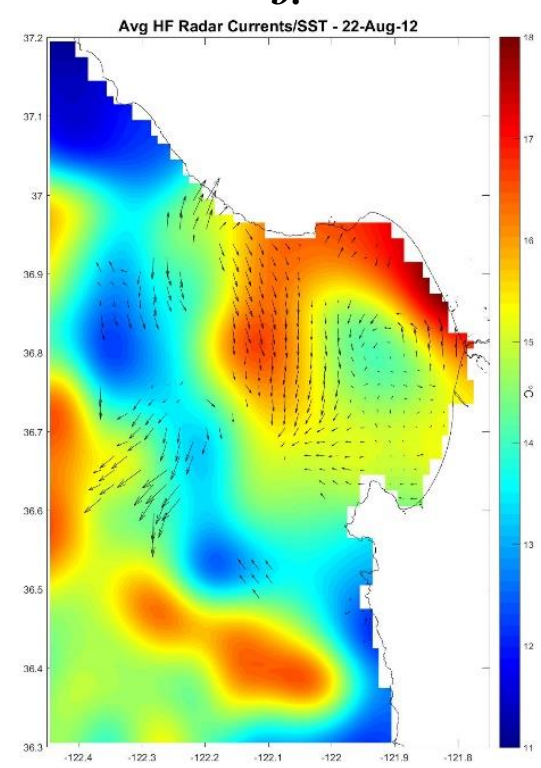

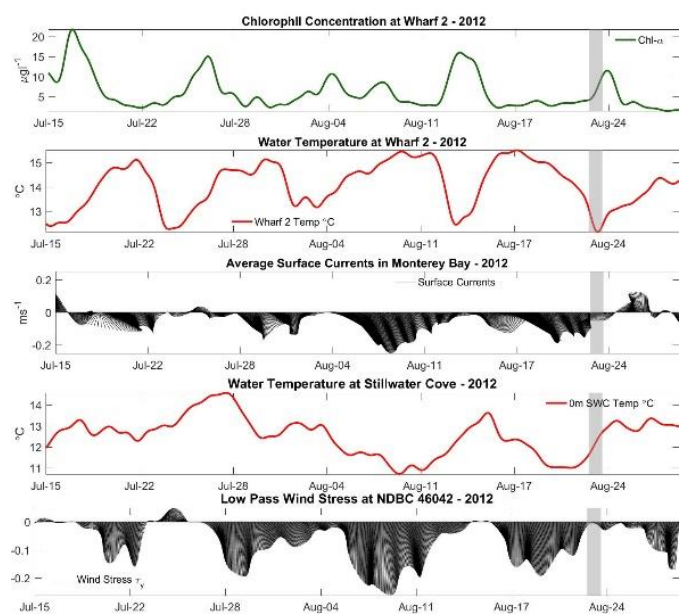

c.

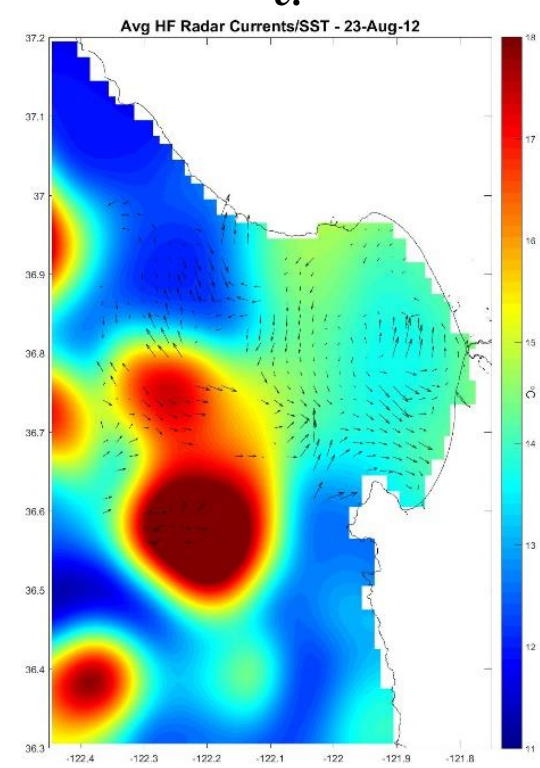

Figure 10. Time series plots of SST with surface current for August 21 (a), August 22 (b), and August 23 (c) of 2012. 
An example of the relationship between water temperature and surface currents during the persistent upwelling period is shown in the plots of SST and daily averaged surface currents (with tidal velocities removed) over a 3 day time span in 2012 (Figure 10). Conditions transitioned from a high temperature, low chlorophyll condition at Wharf 2 to a low temperature, high chlorophyll condition. This transition is slightly preceded by a shift in both wind stress and mean surface current flow and follows the downwelling/relaxation circulation patterns described in Paduan et al. (2016). The initial circulation is cyclonic within the Monterey Bay and anticyclonic without. Warm water retention within the bay is evident. Cooler water is apparent near upwelling center to the north while warmer water is present to the south. After one day the cold waters at both upwelling centers are more pronounced, circulation within the bay is weaker, and a strong thermal gradient is present in the north of the bay. By the third day surface current patterns have broken down and cold water has now displaced much of the warm water in the bay.

\section{DISCUSSION}

The results of this study demonstrate a close relationship between temperature and chlorophyll in southern Monterey Bay which suggests that nearshore phytoplankton supply is governed by advective mechanisms. Wind driven surface current circulation was the primary driver of phytoplankton supply to the nearshore environment of the inner Monterey peninsula during months where upwelling intensity was persistent. Circulations patterns alternated between those associated with upwelling and downwelling/relaxation which have different impacts throughout the region (Figures 11 and 12). 


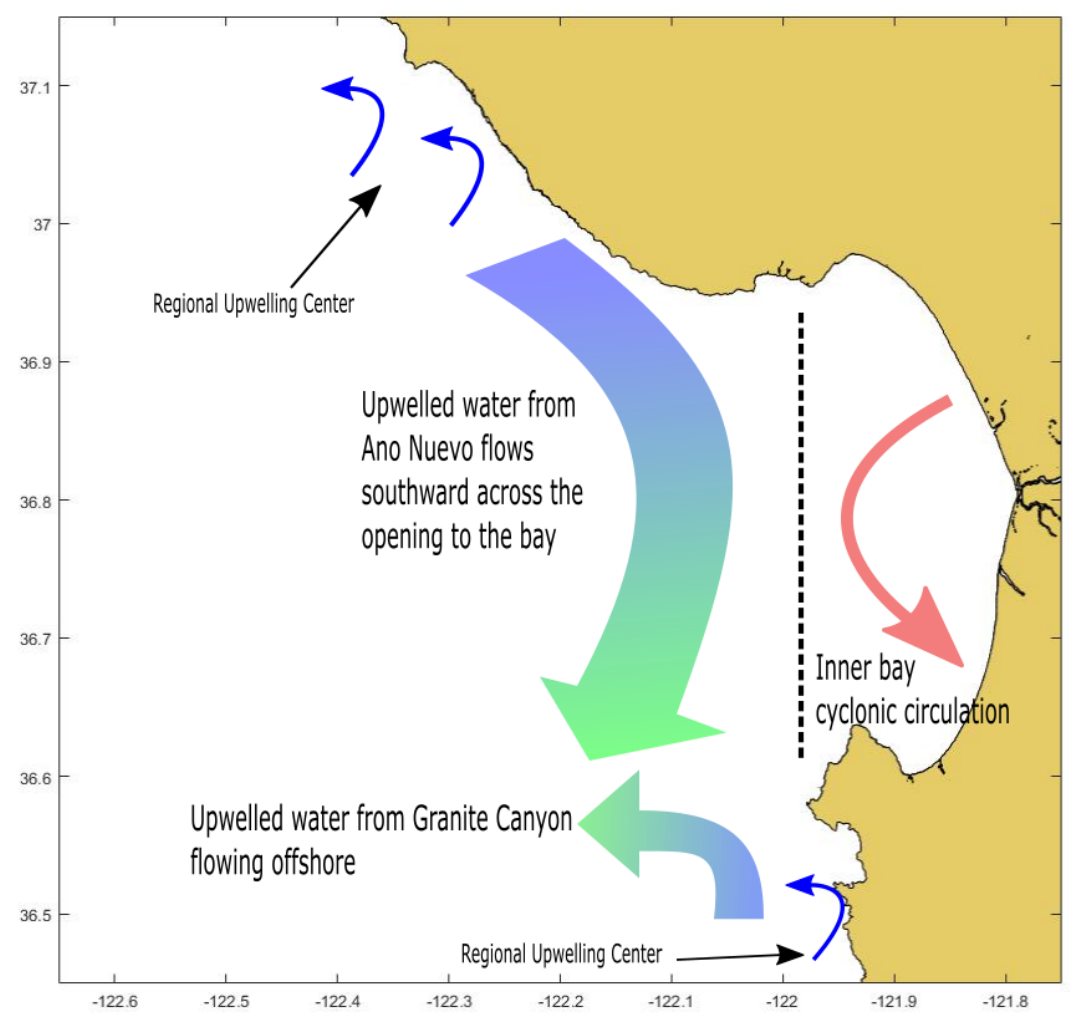

\section{Figure 11. Schematic of water transport during persistent upwelling events}

Abiotic, nutrient rich water is brought to the surface at two regional upwelling centers to the north and south of Monterey Bay. This water is advected offshore and equatorward and as the water mass moves phytoplankton blooms. Warmer surface water circulates cyclonically within the bay (Paduan \& Cook 1997, Paduan et al. 2016) and these two contrasting circulation patterns set up a transport barrier (dashed line, Figure 12).

This is contrasted with the circulation pattern observed during upwelling reversals. In this case flow both reverses direction (poleward rather than equatorward) and the barrier between the inner area of the bay and the regional ocean breaks down, causing surface water to advect from south of Monterey Bay into the southern bight and make its way north along the coast (Figure 13). 


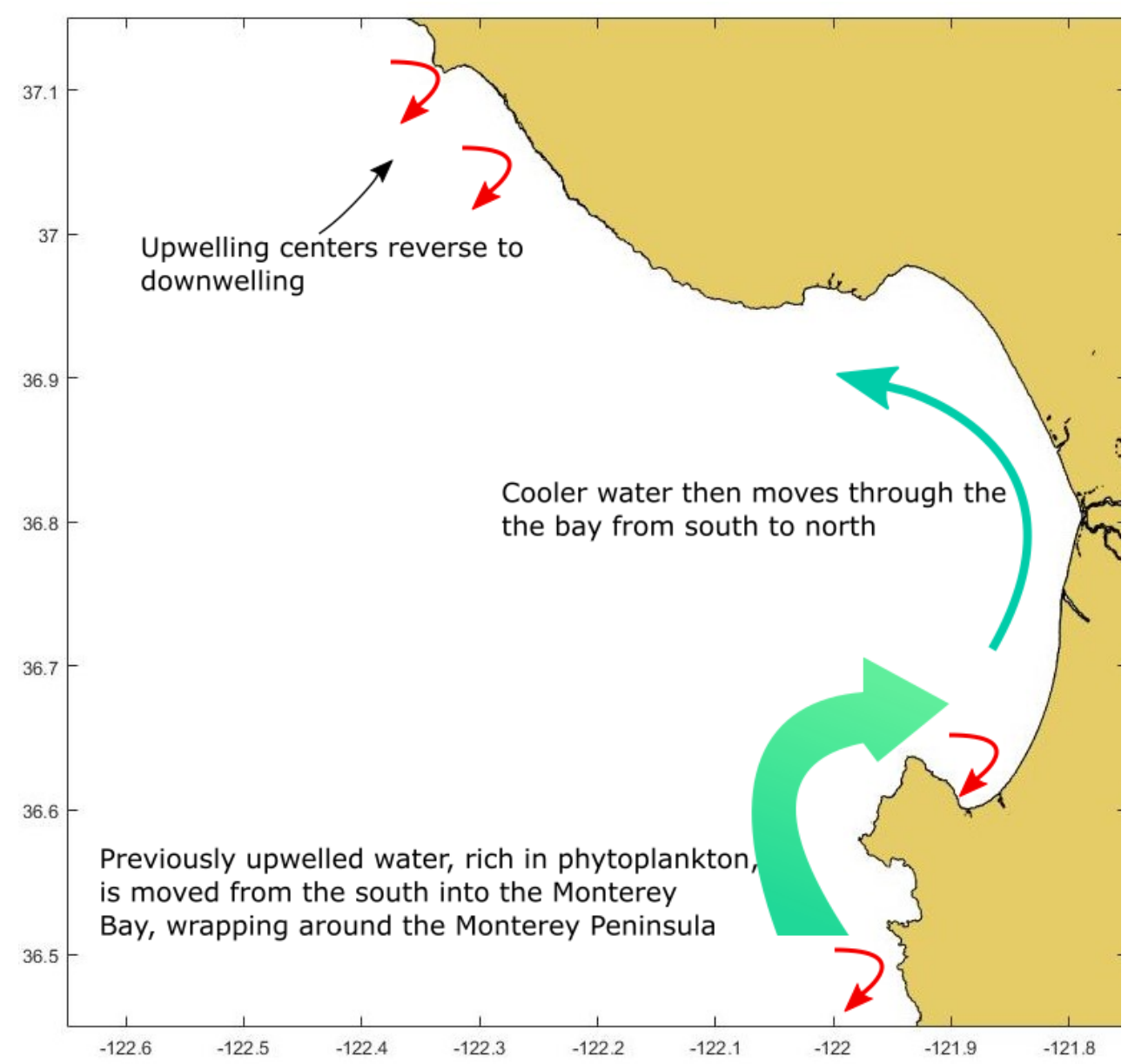

Figure 12. Schematic of water transport during wind reversals/relaxations.

The surface water being advected into the Monterey Bay, while still cooler than the water it is displacing, is at this point rich in phytoplankton. The surface flows shown by Paduan et al. (2016) suggest this flow will continue northward along the shore at a somewhat reduced velocity.

The proposed mechanisms for phytoplankton delivery to the south Monterey Bay is supported by chlorophyll and temperature data from Wharf 2, regional wind stress measurements, regional average surface currents (Figure 8), and the circulation patterns described during upwelling and relaxation (Paduan et al., 2016). Upwelling favorable wind stress and corresponding equatorward mean surface currents are both observed during periods of increasing temperature at Wharf 2. This is consistent with the first schematic in which water recirculates and warms within the bay. The rapid decreases in temperature and subsequent increases in chlorophyll are accompanied by decreases or reversals in wind stress and mean 
surface currents. This suggests that, when upwelling favorable conditions are persistent, the circulation patterns described in Paduan et al. (2016) are the primary driver of phytoplankton to the coastal environment in south Monterey Bay. While the same degree of coherence between winds, surface currents, and nearshore temperature was not observed in 2013, the significant relationship between temperature and chlorophyll suggests that observed phytoplankton blooms were still the result of advection. It is likely that, due to the intermittency of upwelling favorable conditions in 2013, advective dynamics were not as clearly defined and thus harder to resolve.

It has been documented that upwelling events can occur along the shelf of the Monterey Bay outside the typical upwelling season, with direct impacts on the biological productivity of the region. A study by Cheriton et al. (2014) found that, during the 5 week study period occurring in mid-fall (Sep-Oct), two sustained upwelling favorable wind events occurred causing shoaling of isotherms and isohalines as cold, high-salinity water filled the water column from below while the surface waters remained warm and well stratified. These periods of upwelling were punctuated by wind reversals which caused short term downwelling and mixing of the water column. Both downwelling events were associated with increased surface chlorophyll down to $20 \mathrm{~m}$ depth. This suggests that, contrary to earlier models of seasonal upwelling for this area, upwelling does not cease in the fall but rather is somewhat weaker and interrupted by reversals. The result being that, while cold saline water does fill the water column from the bottom up to depths sufficient to impact the euphotic zone during these time periods $(<30 \mathrm{~m})$, it rarely breaks the surface.

Synoptic scale dynamics in nearshore regions are complex, often making it challenging to connect physical forcing with key ecosystem parameters such as chlorophyll. That the relationship between coastal temperature and regional wind stress was only clearly discernable during a season of highly persistent upwelling serves to highlight the importance of the joint probability approach utilized in Paduan et al. (2016). It is clear from the regional wind stress and mean surface currents in 2013 that a different pattern of governing mechanisms was driving surface currents and nearshore temperature. That temperature was more strongly correlated with phytoplankton supply to the nearshore during this time suggests that, while the increases in phytoplankton may not be attributable to the particular advective mechanism described above, it is likely still an advective process ultimately governed by regional forcing mechanisms interacting with local conditions. The potential of the southern upwelling center off Granite 
Canyon as a source of upwelled water for the south Monterey Bay, as is suggested by the surface current patterns described in Paduan et al. (2016), is contrary to the described circulation patterns in Monterey Bay (Rosenfeld et al. 1994; Paduan \& Rosenfeld 1996; Grahan \& Largier 1997). While this study did not set out to determine the geographic source of the relatively cold water associated with high chlorophyll at Wharf 2, the potential alternative source for upwelled water could have implications in the composition of phytoplankton communities advected into the south Monterey Bay.

Despite a high degree of inter-annual variability during this study, the results clearly demonstrate the importance of synoptic scale wind driven circulation events on phytoplankton abundance in nearshore ecosystems. The response of upwelling circulation patterns to even mild disturbances has a dramatic effect in shifting the delivery of phytoplankton to the nearshore. That observed phytoplankton abundance was significantly higher during the period of intermittent upwelling fits with previous work characterizing coastal ecosystems in various upwelling environments (Menge \& Menge, 2013). While this study did not characterize the spatial extent of these high chlorophyll events, the previous work by Woodson et al. (2009) demonstrate that, in the north eastern portion of Monterey Bay, shifts in upwelling circulation and pressure gradients resulted in the rapid movement of a thermal front distances of $\sim 5 \mathrm{~km}$ per day or greater. Given that the distance between Pt. Piños and Wharf 2 is $\sim 6 \mathrm{~km}$, movement of a water mass at a similar rate could impact the entire inner coastline of the Monterey Peninsula in little more than 24 hours.

These results imply that subsidies of phytoplankton to the coastal sub and inter tidal environments may be highly episodic and varied over small spatial scales. These events suggest that much finer spatiotemporal modeling of marine ecosystems around headlands and open embayments near to upwelling centers is necessary to accurately capture how shifts in regional weather patterns may impact productivity across trophic levels in those areas. 


\section{REFERENCES}

Barth, John A., et al. "Delayed upwelling alters nearshore coastal ocean ecosystems in the northern California current." Proceedings of the National Academy of Sciences 104.10 (2007): 3719-3724.

Breaker, Laurence, and William W. Broenkow. "The circulation of MontereyBay and related processes." (1994). Oceanography and Marine Biology: An Annual Review 32

Cheriton, Olivia M., et al. "Suspended particulate layers and internal waves over the southern Monterey Bay continental shelf: An important control on shelf mud belts?." Journal of Geophysical Research: Oceans 119.1 (2014): 428-444.

Drake, Patrick T., Margaret A. McManus, and Curt D. Storlazzi. "Local wind forcing of the Monterey Bay area inner shelf." Continental Shelf Research 25.3 (2005): 397-417.

Emery, W. J., and R. E. Thomson. "Time-series analysis methods." Data Analysis Methods in Physical Oceanography 371 (2001), Pergamon, ISBN:0080314341.

Graham, William M., and John L. Largier. "Upwelling shadows as nearshore retention sites: the example of northern Monterey Bay." Continental Shelf Research 17.5 (1997): 509532.

Huyer, A. (1983). Coastal upwelling in the California Current system. Progress in Oceanography, 12(3), 259-284.

Krenz, Christopher, et al. "Ecological subsidies to rocky intertidal communities: Linear or non-linear changes along a consistent geographic upwelling transition?" Journal of Experimental Marine Biology and Ecology 409.1 (2011): 361-370.

Large, W. G., and S. Pond. "Open ocean momentum flux measurements in moderate to strong winds." Journal of physical oceanography 11.3 (1981): 324-336.

McPhee-Shaw, E. E., Nielsen, K. J., Largier, J. L., \& Menge, B. A. (2011). Nearshore chlorophyll-a events and wave-driven transport. Geophysical Research Letters, 38(2).

Menge, B. A., Chan, F., Nielsen, K. J., Lorenzo, E. D., \& Lubchenco, J. (2009). Climatic variation alters supply-side ecology: impact of climate patterns on phytoplankton and mussel recruitment. Ecological Monographs, 79(3), 379-395. 
Menge, Bruce A., and Duncan N.L. Menge. "Dynamics of coastal meta-ecosystems: the intermittent upwelling hypothesis and a test in rocky intertidal regions." Ecological Monographs 83.3 (2013): 283-310.

Narváez, D. A., Poulin, E., Leiva, G., Hernández, E., Castilla, J. C., \& Navarrete, S. A. (2004). Seasonal and spatial variation of nearshore hydrographic conditions in central Chile. Continental shelf research, 24(2), 279-292.

Olivieri, R. A., \& Chavez, F. P. (2000). A model of plankton dynamics for the coastal upwelling system of Monterey Bay, California. Deep Sea Research Part II: Topical Studies in Oceanography, 47(5),1077-1106.

Paduan, Jeffrey D., and Leslie K. Rosenfeld. "Remotely sensed surface currents in Monterey Bay from shore-based HF radar (Coastal Ocean Dynamics Application Radar)." Journal of Geophysical Research: Oceans 101.C9 (1996): 20669-20686.

Paduan, Jeffrey D., and Michael S. Cook. "Mapping surface currents in Monterey Bay with CODAR-type HF radar." Oceanography 10.2 (1997): 49-52.

Paduan, Jeffrey D., Michael S. Cook, and V. Mario Tapia. "Patterns of upwelling and relaxation around Monterey Bay based on long-term observations of surface currents from high frequency radar." Deep Sea Research Part II: Topical Studies in Oceanography (2016).

Palacios, S. L., et al. "Seasonal and Inter-Annual Patterns of Chlorophyll and Phytoplankton Community Structure in Monterey Bay, CA Derived from AVIRIS Data During the 2013-2015 HyspIRI Airborne Campaign." American Geophysical Union, Ocean Sciences Meeting 2016, abstract\# EC34D-1215. 2016.

Paquin, A. 2012. Seasonal and Event Scale Forcing of Phytoplankton Abundance and Taxonomic Composition in the Surfzone of an Open-Coast, Rocky Shore (Master's Thesis). Sonoma State University, Rohnert Park, CA

Pauly, Daniel, and Villy Christensen. "Primary production required to sustain global fisheries." Nature 374.6519 (1995): 255-257.

Pennington, J. Timothy, and Francisco P. Chavez. "Seasonal fluctuations of temperature, salinity, nitrate, chlorophyll and primary production at station H3/M1 over 1989-1996 in Monterey Bay, California." Deep Sea Research Part II: Topical Studies in Oceanography 47.5 (2000): 947-973. 
Pawlowicz, R., B. Beardsley, and S. Lentz, "Classical Tidal Harmonic Analysis Including Error Estimates in MATLAB using t_tide", Computers and Geosciences, 28, 929-937 (2002).

Pilskaln, Cynthia H., et al. "Carbon export and regeneration in the coastal upwelling system of Monterey Bay, central California." Journal of Marine Research 54.6 (1996): 11491178.

Rosenfeld, L. (1983), CODE-1: Moored array and large-scale data report, Tech. Rep. 8323, 186 pp., Woods Hole Oceanogr. Inst., Woods Hole, Mass.

Rosenfeld, L. K., Schwing, F. B., Garfield, N., \& Tracy, D. E. (1994). Bifurcated flow from an upwelling center: a cold water source for Monterey Bay. Continental Shelf Research, 14(9), 931-964.

Ryan, John P., et al. "Influences of upwelling and downwelling winds on red tide bloom dynamics in Monterey Bay, California." Continental Shelf Research 29.5 (2009): 785795.

Ryan, J. P., McManus, M. A., \& Sullivan, J. M. (2010). Interacting physical, chemical and biological forcing of phytoplankton thin-layer variability in Monterey Bay, California. Continental Shelf Research, 30(1), 7-16.

Service, S. K., J. A. Rice, and F. P. Chavez. "Relationship between physical and biological variables during the upwelling period in Monterey Bay, CA." Deep Sea Research Part II: Topical Studies in Oceanography 45.8 (1998): 1669-1685.

Sevadjian, J. C., McManus, M. A., Ryan, J., Greer, A. T., Cowen, R. K., \& Woodson, C. B. (2014). Across-shore variability in plankton layering and abundance associated with physical forcing in Monterey Bay, California. Continental Shelf Research, 72, 138-151.

Shea, R. E., \& Broenkow, W. W. (1982). The role of internal tides in the nutrient enrichment of Monterey Bay, California. Estuarine, Coastal and Shelf Science, 15(1), 57-66.

Skogsberg, Tage. Hydrography of Monterey Bay, California: Thermal Conditions, 19291933. The American philosophical society, 1936.

Skogsberg, Tage, and Austin Phelps. "Hydrography of Monterey Bay, California. Thermal Conditions, Part II (1934-1937)." Proceedings of the American Philosophical Society (1946): 350-386. 
Thomas, A. C., M-E. Carr, and P. Ted Strub. "Chlorophyll variability in eastern boundary currents." Geophysical Research Letters 28.18 (2001): 3421-3424.

Urmy, Samuel S., and John K. Horne. "Multi-scale responses of scattering layers to environmental variability in Monterey Bay, California." Deep Sea Research Part I: Oceanographic Research Papers 113 (2016): 22-32.

Wieters, E. A., D. M. Kaplan, S. A. Navarrete, A. Sotomayor, J. Largier, K.J. Nielsen, and F. Véliz (2003), Alongshore and temporal variability in chlorophyll a concentration in Chilean nearshore waters, Marine Ecology Progress Series, 249, 93-105, doi:10.3354/meps249093.

Woodson, C. B., et al. "Northern Monterey Bay upwelling shadow front: Observations of a coastally and surface-trapped buoyant plume." Journal of Geophysical Research: Oceans 114.C12 (2009). 


\section{APPENDIX A \\ ADDITIONAL ANALYSES}

Waves

Moving monthly average wave heights ranged from $1.2 \mathrm{~m}$ in August of 2013 to $3.0 \mathrm{~m}$ in October of 2013. Greatest average wave heights predictably occurred during the winter months of December, January, and February. While April and May of 2013 had lower monthly average wave heights, they did have higher maximum wave heights.

Wave direction for our study site is predominantly out of the north-west, from a direction ranging from 290 to 330 degrees (Figure 14).

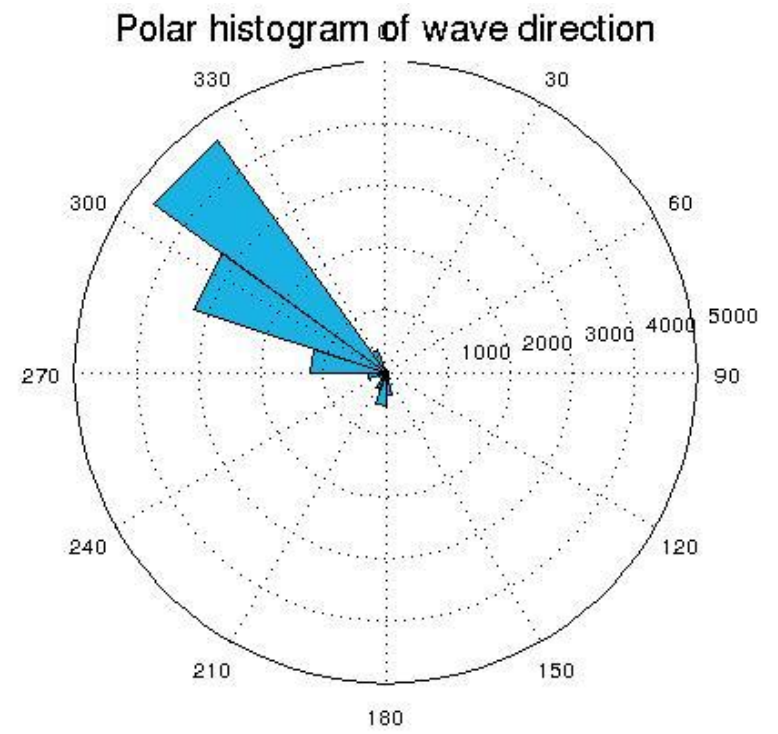

Figure 13. Polar histogram of wave direction taken from N42.

These factors were analyzed as initial research was focused on potential for surface advection of phytoplankton due to Stokes drift. However, correlation analysis revealed that, for this study site, waves were only loosely correlated with chlorophyll and mostly followed wind stress, which was a somewhat better predictor of chlorophyll.

Wave Height Moving Monthly Average:

Wave height was highly variable across all months 


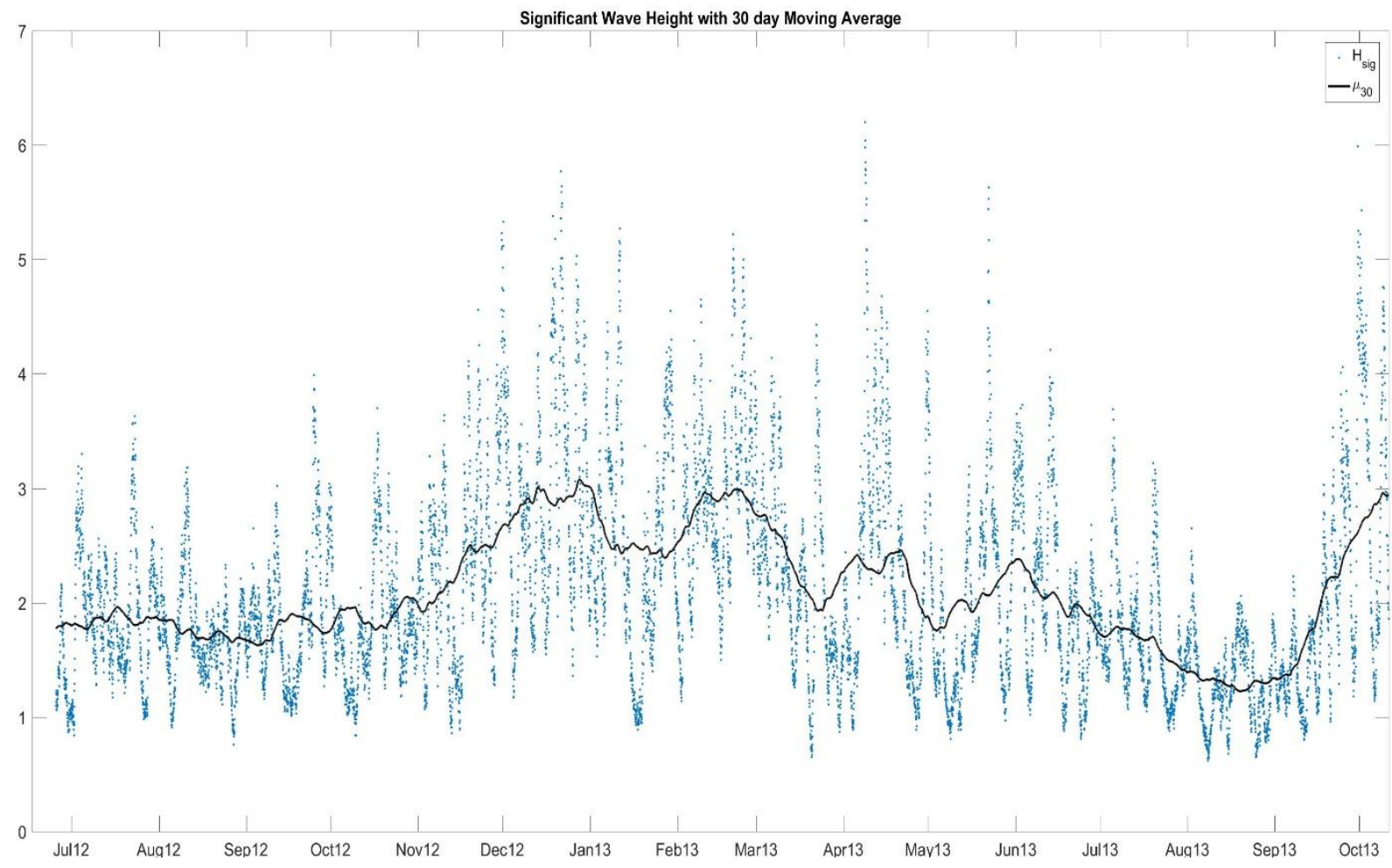

Figure 14. Hourly averages of significant wave height with running monthly averages (red) measured at N42.

Wave Height Frequency Analysis:

In all months, wave height exhibited periodic fluctuations at tidal (12 hour) and weekly (128 hour) periods (Figure 16). 


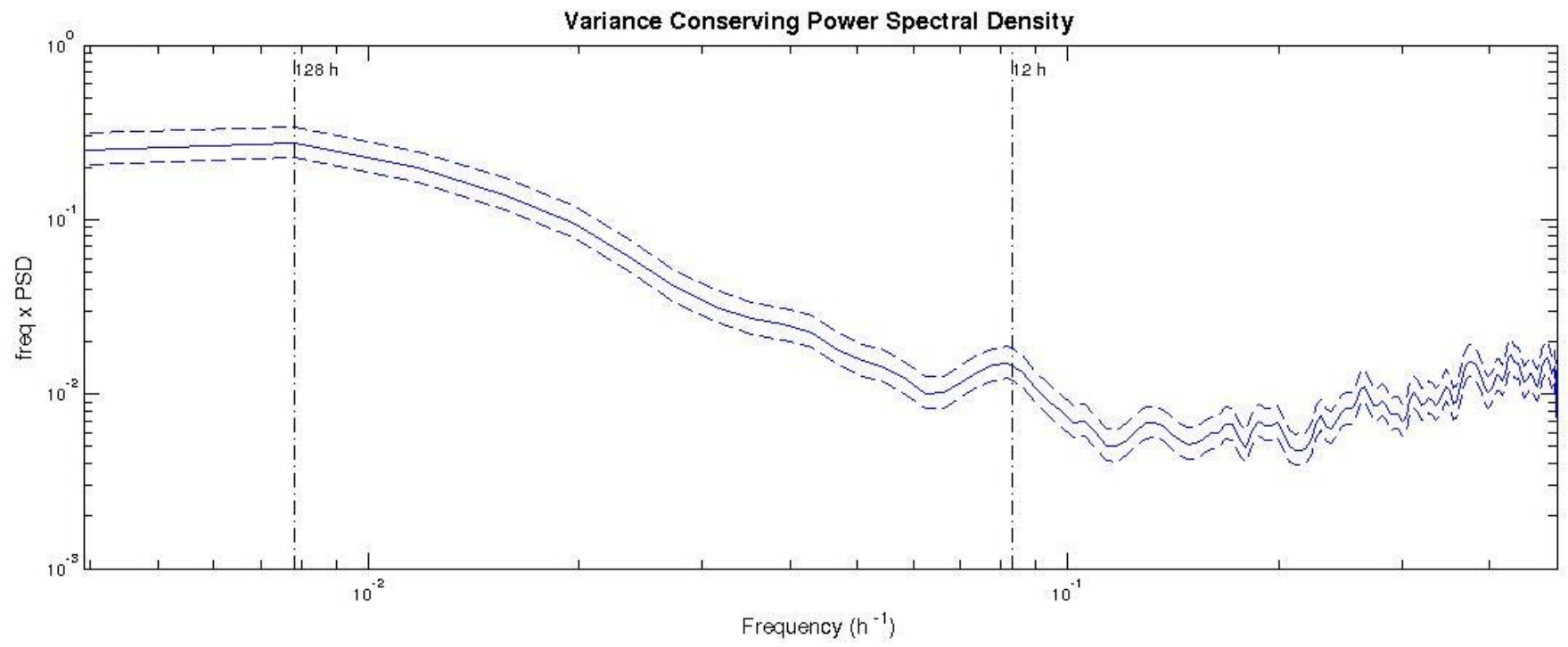

Figure 15. Variance conserving power spectral density of significant wave height. 